\title{
UNIVERSITY OF TAMPERE
}

This document has been downloaded from

TamPub - The Institutional Repository of University of Tampere

\section{Post-print}

The permanent address of the publication is

http://urn.fi/URN:NBN:fi:uta-201309261382

Author(s): $\quad$ Laitinen, Arto

Title: Against representations with two directions of fit

Year: $\quad 2014$

Journal Title: Phenomenology and the Cognitive Sciences

DOI: $\quad$ http://dx.doi.org/10.1007/s11097-013-9328-9

All material supplied via TamPub is protected by copyright and other intellectual property rights, and duplication or sale of all part of any of the repository collections is not permitted, except that material may be duplicated by you for your research use or educational purposes in electronic or print form. You must obtain permission for any other use. Electronic or print copies may not be offered, whether for sale or otherwise to anyone who is not an authorized user. 


\section{Against representations with two directions of fit}

The idea that there are representations with a double direction of fit has acquired a pride of place in contemporary debates on the ontology of institutions. (see Searle 1983; 1995, 2010 ${ }^{1}$; see also e.g. Tuomela 2007, 185-6). ${ }^{2}$ This paper presents an argument against that idea.

The main aim is to show that the idea of double direction of fit suffers from a simple problem which has thus far gone unnoticed. The problem is independent of whether we focus on speech acts or propositional attitudes or other possible kinds of representations that might have a direction of fit. Roughly, the distinction between the directions of fit of "practical" and "theoretical" representations concerns the question of which end has to change, the representation or the world, in cases of discrepancy. These are cases where the representation and world do not "fit" or "match" in the relevant sense of having identical content. ${ }^{3}$ For example, the representation can be an assertion, (or report, or belief or other theoretical representation) or an order (or desire or other practical representation) that there are bananas in the shopping basket, but if it is the case that there are no bananas in the shopping basket, there is a discrepancy between the representation and the world. In the case of theoretical representations (assertions, reports, beliefs etc.) aiming at truth, the representation has to change in such situations (in that example, to hold that there are no bananas in the shopping basket), and in the case of practical representations (orders, shopping lists, desires, intentions etc.) it is not the representation that should change in such situations, but rather the world (e.g. by the shopper putting bananas to the shopping basket). If the required kind of change takes place, the representation and world fit each other. So far, so good. By contrast, the suggestion that there are representations with both directions of fit amounts to a suggestion that in cases of discrepancy both ends should change - the representation and the world. But if both ends indeed do change as required, it merely creates a different discrepancy (so that in the example, the

\footnotetext{
${ }^{1}$ The central idea of Searle's book Making the Social World is that declarations and other representations with the double direction of fit explain the existence of institutions. See especially pp.12-13, 68-69, 85-86, 93, 95-7, 104, 109, 170.

${ }^{2}$ Raimo Tuomela mostly writes about collective attitudes as having one or the other direction of fit, but occasionally admits ones that have both: "...group beliefs based on constitutive construction in the purely institutional case (where the content is being created) have the world-to-mind direction of fit [wmdf] — but, given the model of performative declarations, they also have the mind-to-world direction of fit [mwdf] (for instance, the belief that squirrel pelt is money also represents the group fact that squirrel pelt is money)."(Tuomela 2007, 185)" "That squirrel pelt thus comes to count as money is a constitutive belief content (with wmdf and also mwdf)" (ibid., 186).

${ }^{3}$ The representation and the world have identical content when it is the case that $\mathrm{p}$, and $\mathrm{p}$ is also the propositional content of the representation. They also have identical content when it is the case that $-\mathrm{p}$ and $-\mathrm{p}$ is also the propositional content of the representation. They do not have identical content when it is the case that $\mathrm{p}$, but the propositional content of the representation is $-\mathrm{p}$. And they do not have identical content when it is the case that $-\mathrm{p}$, but the propositional content of the representation is p. See subsection 3 below.
} 
representation is changed to hold that there are no bananas in the shopping basket, and the world changes so that there are bananas in the shopping basket). In the case of one direction of fit, this kind of problem does not arise as the required change is to remove the discrepancy by changing one end and keeping the other as it is, so that the representation and world come to fit each other - but in the case of two directions of fit, both ends do change which creates a new discrepancy. So both ends should change again, - again amounting to the original discrepancy (in the example, the representation is again that there are bananas in the shopping basket, while it is the case that there are no bananas in the shopping basket). And so on, ad infinitum. The suggestion that there are representations with both directions of fit has thus the rather intolerable consequence that the fitting relation between the representation and the world is impossible to regain once a discrepancy has arisen. This paper tries to establish, in $\S 3-5$, that we should reject the idea of a double direction of fit because of this problem.

The section $\S 1$ first elucidates the notion of directions of fit and clarifies how the criticism to be presented here differs from earlier criticisms of the idea of the double direction of fit. The second section of paper will shed some light on why and how representations with both directions of fit have seemed to play a part in explaining the existence of institutional reality. This paper will not take a stand on what it is that creates institutional reality: perhaps declarations and collective acceptance play a central role as Searle thinks, perhaps they do not. This paper is addressed to both defenders and critics of Searle's and others' idea that we create the institutional reality by representing that reality as created. Whatever it is that creates and maintains institutional reality, it is best understood without the idea of representations with both directions of fit - it is a bad idea for the independent reasons discussed in more detail below. Having a causal or constitutive role in the creation of institutional reality is conceptually a different idea from that of having a double direction of fit (§2).

The next sections present the argument against any states with both directions of fit, relying first on a normative understanding of the distinction. The argument will have three steps $(\S 3-\S 5)$. The section that follows shows that the criticism also applies on the non-normative dispositional understanding of the notion ( $\$ 6)$, and then the paper asks whether some third kind of reading would be available and whether the infallibility of constitutive attitudes and declarations would be of help in rescuing the idea of double direction of fit (\$7). Then the paper discusses whether the possible infallibility of the representations in question might help against the criticism presented here, 
arguing that it does not (§8). Finally, the paper assesses briefly the consequences of dropping the notion of representations with both directions of fit (\$9).

\section{Introducing the idea of directions of fit}

The "direction of fit" - analysis of propositional attitudes such as beliefs and desires or intentions (and speech acts such as assertives and directives) has been used in many areas of investigation since the terminology was introduced in the writings of Austin (1953 - though not in this sense), reported to be a familiar line of argument in the 60's (see Williams 1966), and developed by Searle $(1975,1983)$ and Platts (1979) in the 70's, and by other authors in the 80's and after.

Various kinds of representations can in principle have a direction of fit: speech acts such as assertions, orders, promises; propositional attitudes such as beliefs, desires, and intentions; written texts such as detectives' reports and shopping lists; and arguably although it does not matter to this paper, even artefacts such as traffic signs which give practical guidance or such as speed indicators, which aim at representing what is the case. ${ }^{4}$ In the case of speech acts and written language, the direction of fit concerns the relation between words and world, and in the case of mental states it concerns the relation between mind and world. We can generalize and say that the direction of fit always concerns the relation between a representation and the world. The direction of fit of assertions, beliefs, reports and speed indicators is "theoretical": in their case the representation is to fit the world (word-to-world, mind-to-world, or in the general phrase I will use in this paper, "representation-to-world" direction of fit), whereas the direction of fit of orders, promises, desires, intentions, shopping lists or speed limit signs is "practical": in their case, the world is to fit the representation (world-to-word, world-to-mind, or "world-to-representation" direction of fit). ${ }^{5}$ The argument of this paper is intended to be general and apply to any of the kinds of representations that can have a direction of fit: no representation of any sort can have both directions of fit. ${ }^{6}$

Elizabeth Anscombe's $(1957, \S 32)$ example of a shopping list with various items in it, and a shopping basket which ultimately ought to have all the same items as the shopping list, has been widely and rightly regarded as a nice illustration of the difference between two directions of fit

\footnotetext{
${ }^{4}$ Searle (2010) writes only occasionally about other things apart from propositional attitudes or speech acts as having directions of fit (e.g. rules, p. 97, or "daily use of vocabulary cumulatively", p.104).

${ }^{5}$ Searle holds that there are in fact four possible directions of fit: in addition to the mind/word-to-world, world-to$\mathrm{mind} /$ word, and the double direction of fit there is a "presup" direction of fit. For the purposes of this paper, the "presup" case need not be considered.

${ }^{6}$ I thank an anonymous referee for pointing out the need to clarify the nature of the argument in this respect.
} 
although Anscombe does not use the phrase "direction of fit". ${ }^{7}$ It may help to think of this in terms of a boss (the shopper's wife in Anscombe's text) having first made the list, and then sent a personal assistant to the shop - the assistant's task is to obey the shopping list and regard it as fixed, and collect the mentioned items.

Such a shopping list contrasts with the record of a detective spying on what the shopper puts in the shopping basket: the detective's record ought to have all the same items as the shopping basket. The detective obviously should not regard his or her list or record as fixed in advance.

When both the shopper and the detective have been successful, the shopping list, the basket and the detective's record have the same items in them. The difference with the shopping list and the detective's record concerns the unsuccessful case: what happens if the list in question contains, say, "bananas" when there are no bananas in the basket. The shopper should not delete "bananas" from the list but add bananas to the basket. And the detective in turn should not add anything to the basket, but delete such unfit items from the detective's record. Anscombe asks what distinguishes the shopping list from the detective's list, and answers:

"It is precisely this: if the list and the things that the man actually buys do not agree, and if this and this alone constitutes a mistake, then the mistake is not in the list but in the man's performance (...) whereas if the detective's record and what the man actually buys do not agree, then the mistake is in the record." (Anscombe, 1957, p. 56)

\footnotetext{
${ }^{7}$ Moran and Stone (2009) have argued that not only is the phrase, but also the very idea of a direction of fit, absent from Anscombe's Intentions. They argue that Anscombe's distinction between speculative and practical knowledge differs from a "contemporary functionalist account" of the distinction between the directions of fit of desires and beliefs and the world. Moran and Stone claim that "While any talk of 'knowledge' must find room for application of an idea of fit or accord, the fit present in cases of practical knowledge (or absent in cases of its failure) isn't simply a matter of reversing the priority between the same two items which figure in cases of speculative knowledge; practical knowledge involves a distinctive class of items known."(Moran and Stone 2009, 156-157, italics added). Moran and Stone may well be right about what Anscombe says about practical and speculative knowledge in general, but nonetheless the shopping list case by Anscombe does seem to include, pace Moran and Stone, precisely same two items (things listed, things bought) with reversed priority in the case of the shopper and the detective. While the list is according to Anscombe indeed an expression of an intention if written by the shopper, and "has the role of an order" if written by the wife (or the boss), it has a "different relation" if written by a detective in which case it is a "record" (Anscombe 1957, p.56). What is mistaken (if the discrepancy constitutes a mistake) is either the performance or the record, but the relevant relation of "fit" holds between the things listed and the things bought, according to Anscombe. These are thus the same two items in both cases. There are many ways to extrapolate this to other cases which do not include a written list. (Further, one may note that Moran and Stone exclusively discuss a functionalist account of directions of fit, and ignore the normative accounts). I thank an anonymous referee for pointing the relevance of Moran's and Stone's paper and the debatability of whether Anscombe's case illustrates successfully the idea of two directions of fit.
} 
The point is that the detective's record functions like beliefs or assertions about the contents of the basket, the shopping list functions like desires, intentions or orders about the contents of the basket. The direction of fit of theoretical representations (record, belief, assertion) is such that their contents should fit the world, whereas the direction of fit of practical representations (shopping list, desire, intention, order) is such that their contents should be kept fixed, while the world should come to fit them. The former have the representation-to-world-direction of fit, and the latter have the world-torepresentation-direction of fit. ${ }^{8}$

While the concept of directions of fit itself concerns philosophy of mind (or of mental states) and the philosophy of language (or of speech acts), it has been applied to various other areas 9 .

In two contexts especially the idea of representations with both directions of fit has seemed appealing: these are first the issue of moral motivation and second the theory of institutional reality. In the first context the suggestion of mental states with two directions of fit has previously been famously criticized, but not so in the latter.

In the area of moral motivation, it is tempting to see moral judgements both as belief-like and desire-like, as "besires". The temptation is to say that moral judgements are both criticizable like ordinary beliefs, and also motivate unlike ordinary beliefs. ${ }^{10}$ Michael Smith (1987) criticized influentially the idea that any propositional attitude could have opposite directions of fit in relation to its propositional object, and that criticism has pretty much stuck. In response to Smith, three moves have been made. First, Huw Price (1989) argued that this only shows that belief that p is not a desire that $\mathrm{p}$, not that belief that $\mathrm{p}$ cannot be a desire that q (later this line has been developed e.g. by Tenenbaum 2006). Today there seems to be widespread consensus that there are no states such as "besires" which would have both directions of fit concerning the same content, but they might well have different directions of fit concerning different contents. Secondly, for instance Lloyd Humberstone (1992) and Nick Zangwill (1998) have argued for a different understanding of the distinction: they have challenged Smith's dispositional characterization and suggested a normative

\footnotetext{
${ }^{8}$ Humberstone (1992) calls the directions of fit "thetic" and "telic", partly for reasons of brevity, partly for another reason, "namely a difficulty in remembering always that "mind-to-world" abbreviates "mind-to-fit-world", rather than alluding to the characteristic direction of causation "from-mind-to-world", which is how I naturally interpret the phrase, but which picks out typically (though not invariably ... ) precisely the reverse direction of fit-as noted in Searle (1979, pp. 97, 122).". I use the terms "theoretical" and "practical" as well as the phrases "representation-to-world" and "worldto-representation" intended to cover mental, linguistic and any other representations.

${ }^{9}$ Other areas include e.g. the issues of "ethics of belief", the analysis of knowledge, the doctrine of double effect, etc. See Humberstone 1992.

${ }^{10}$ For discussion, see Dancy 1993.
} 
characterization in its stead. And finally, for example Sobel and Copp (2001) have argued against any analyses of beliefs and desires in terms of directions of fit. As a consequence, there is some skepticism today whether the direction of fit - conceptualization is fruitful at all: whether a good account of the difference has been or will be found.

In the area of the ontology of institutional reality, it is indeed the same propositional content that is relevant, so the first move is of no help there. Collective acceptance or declaration that squirrel pelt is money is supposed to have both directions of fit concerning the very proposition that squirrel pelt is money. Secondly, this paper also takes into account the normative understanding of directions of fit, thus complementing Smith's criticism which relied on a dispositional understanding. This paper will argue that neither the dispositional nor the normative, nor any third kind of reading of the distinction between directions of fit will help to defend the idea of a double direction of fit. And thirdly, this paper tries to remain non-committal on the usefulness of the concept of direction of fit itself, here or in other areas. If the very distinction is useless for other reasons, it would merely strengthen the conclusion, which is to advice against thinking that attitudes central to the constitution of institutional reality have two opposite directions of fit concerning their propositional content.

\section{Why the double direction of fit has seemed like a good idea in social ontology}

Institutional reality in some sense depends on the attitudes and activities of humans, but those attitudes and activities at the same time represent the institutions as existing. To use Raimo Tuomela's example, a group's declaration or collective acceptance that squirrel pelt is money is exceptional in being both in the business of making it true and taking it as true that squirrel pelt is money in that group. The remarkable power of these states has been compared by John Searle $(2010,100)$ to God's powers to create light by merely representing it as existing. ${ }^{11}$ For the purposes of this paper I do not cast doubt on (nor will I defend) the idea that institutional reality has indeed a peculiar ontology in being dependent on declarations or collective acceptance. It is just that this good idea should not be cashed out in terms of a bad idea, the idea of attitudes with both directions of fit.

\footnotetext{
11 "God can create light by saying "Let there be light!" Well, we cannot create light but we have a similar remarkable capacity. We can create boundaries, Kings and corporations by saying something equivalent to, "Let this be a boundary!" "Let the oldest son be the King!" "Let there be a corporation!"'(Searle 2010, 100).
} 
Searle $(1969,1983)$ has earlier analysed the speech acts of "declarations" as having the double direction of fit, and in his book Making the Social World he argues that declarations, or representations with the same logical structure as declarations, are central in analysing the existence of social and institutional reality. These other representations need not be speech acts, but can be for example thoughts. ${ }^{12}$ He writes:

\begin{abstract}
"With the important exception of language itself, all of institutional reality, and therefore, in a sense, all of human civilization, is created by speech acts that have the same logical form as Declarations. Not all of them are, strictly speaking, Declarations, because sometimes we just linguistically treat or describe, or refer to, or talk about, or even think about an object in a way that creates a reality by representing that reality as created. These representations have the same double direction of fit as Declarations, but they are not strictly speaking Declarations because there is no Declarational speech act."(Searle 2010, 12-13, italics added).

"For example, in order for Obama to be President people do not have to think 'We have imposed on him a status function according to the formula $\mathrm{X}$ counts as $\mathrm{Y}$ in $\mathrm{C}^{\prime}$, even though that is exactly what they have done. But they do have to be able to think something. For example, they typically think ' $\mathrm{He}$ is President', and such thoughts are sufficient to maintain the status function, because they have the logical form of status function Declarations, and thus have the double direction of fit characteristic of all Declarations."(Searle 2010, 170, italics added).
\end{abstract}

The following five claims are central to John Searle's theory of institutional reality as presented in his book Making the Social World. ${ }^{13}$ Some of these are widely shared, and many of them may well be worth preserving even if the idea of double direction of fit should ultimately be rejected:

i) Institutional reality exists because humans take and treat it as existing.

\footnotetext{
${ }^{12}$ On several occasions Searle (e.g. 1999, 151; 2007, 26; 2010, 26) has asserted that it is only speech acts, and not prelinguistic mental or intentional states, that can have the double direction of fit. On the other hand, occasionally, (as in 2010, 12-13; quoted above) he seems to admit of mental states having the double direction of fit. If one would want to help Searle have it both ways, one could distinguish between i) prelinguistic forms of intentionality and mental states, ii) linguistic operations and iii) "post-linguistic" or linguistically enabled forms of intentional and mental states (beliefs etc. made possible by the mastery of a language - say, thoughts about world peace or presidents); and claim that while prelinguistic forms of intentionality cannot have the double direction of fit, post-linguistic thoughts (such as thoughts concerning the president) perhaps can. Indeed, Searle $(2010,26)$ states precisely that it is prelinguistic mental states that cannot have the double direction of fit. Another distinction that might be relevant is that between creating and maintaining - it is a plausible view that creation requires public language, but maintenance only thoughts. The claim "we cannot create a state of affairs by thinking it" (Searle 1999, 151) remains contradicted by the claim that we can "...even think about an object in a way that creates a reality by representing that reality as created" (Searle 2010, 13), but these points are really about the causal role of thoughts, not their direction of fit as such. Whatever Searle's view of the possible candidates for double direction of fit, the argument in this paper applies to any alleged representations (linguistic, mental, other) with double direction of fit.

${ }^{13}$ Searle's book contains other central notions such as "status function" and "deontic power" which need not be discussed here.
} 
ii) More specifically, the creation, constitution, and continued existence of institutional reality depend on collective acts, attitudes, or representations such as collective acceptance or declarations. A piece of paper is a dollar bill, and Barack Obama is the president of the United States, because relevant considerations are collectively accepted, or because relevant declarations have been made.

iii) The acts or attitudes or representations involved in the creation of institutional facts and rules have the logical form of the speech act of declarations, even when literally no declaration takes place.

iv) A declaration makes something the case by representing it as being the case.

v) The logical form of declarations is striking in having a double direction of fit concerning the same propositional content: like beliefs or assertions, these attitudes and acts with double direction of fit aim to represent things as they are, and like intentions or desires or commands, these attitudes and acts provide contents to which the world should fit.

This paper neither defends nor criticizes the first four claims but focuses on criticizing the fifth. While the first claim about dependence on humans is pretty uncontroversial, and the second one about collective acceptance is also widely shared in the literature on social ontology (although the nature of "collectivity" needed, and the precise nature of the "acceptance" in question are open to dispute), the comparison with declarations is the major novelty of Making the Social World and is a much more disputable idea. ${ }^{14}$ In principle one could accept the last two claims about declarations, but reject the idea (iii) that declaration-like episodes are of more than marginal relevance to institutional reality. ${ }^{15}$ This paper will not directly confront the thesis (iii), but will rather try to show that even Searleans who accept that thesis should nonetheless reject the idea of the double direction of fit.

That a declaration creates something by representing it as existing (iv) may well be an innocent idea. Pronouncing someone a husband and a wife both represents them as a husband and a wife, and creates the very state of affairs that it represents. It may well be the defining feature of the very class of such speech acts as a separate class that they bring something about by claiming that the

\footnotetext{
${ }^{14}$ Compare to Searle 1995, where performative acts have a role in the creation of "many though not all institutional facts" (54); there he gives the example that "the possibility of creating institutional facts by declaration does not hold for every institutional fact. You cannot, for example, make a touchdown just by saying you are making it"(55). Many reasonable-sounding qualifications like this in Searle's 1995 book have been left aside in the 2010 book in the hope of a more general theory.

${ }^{15}$ It is also unclear what the roles of collective acceptance on the one hand and declaration-like initiatives on the other hand are in Searle's account. See Tsohatzidis 2010.
} 
very state of affairs is in existence. This paper does not directly dispute the existence of such speech acts. $^{16}$

Although ultimately misguided, it is very tempting to cash this idea out in terms of directions of fit (v). The considerable appeal of the idea of opposite directions of fit comes from the remarkable facts of performativity (squirrel pelt is money only if it is collectively accepted as money; a couple is a married couple only if the priest has declared it to be a married couple) and reflexivity (squirrel pelt is collectively accepted as money only if it is money; the priest's successful declaration has taken place only if it is a married couple). Together these features amount to the claim that the collective manages to make something true by taking it as true or representing it as true. Because the representation is of something as existing, it seems to be "theoretical", belief-like or assertionlike. And because it is in the business of altering reality, it seems to share the crucial features with such practical representations as orders, promises, desires and intentions. Given that practical and theoretical representations have the opposite directions of fit, these representations which both represent something as existing and are in the business of altering reality seem to have both of these directions of fit. Searle makes this point explicitly: "the logical structure of the creation of institutional facts is exactly the same as that of the Declaration: the representations have the double direction of fit because they make something the case by representing it as being the case."(Searle 2010, 86, italics added).

This is however to conflate the idea of a direction of fit and the idea of causal self-referentiality. These should not be conflated. The notion of "direction of fit" distinguishes theoretical from practical representations. By contrast, the idea of causal self-referentiality draws a distinction within each of these classes: it distinguishes for example perception and memory from belief, and intentions from desires (Searle 2010, 38 and passim.). Visual experiences and memory experiences are causally self-referential in that these states are satisfied only if they are caused by the state of affairs represented in the content of the state - whereas beliefs are satisfied whenever they are true. Intentions, unlike desires, are satisfied only if the intentions play a causal role in bringing about the intended state of affairs.

\footnotetext{
${ }^{16}$ Note however that Searle's $(2010,12)$ list of examples of declarations may be problematic: Searle first classifies orders and promises as having the direction of fit of desires, and later at the same page classifies them as declarations; and he first claims that apologies do not have either direction of fit, but then classifies them as declarations and thus as having both directions of fit. Whatever Searle's full theory concerning declarations and other speech acts, using examples in this way is puzzling.
} 
Thus some theoretical representations are causally self-referential and some are not, and some practical representations are causally self-referential and some are not. Perhaps then the same holds of the alleged representations with double direction of fit: some could be causally self-referential whereas some are not. Perhaps declarations are self-referential in the same way that intentions are: a priest's declaration is satisfied only if the couple becomes a married couple thanks to that very declaration. (Declarations are not causally self-referential in the same way that perceptions are: the fact that the couple is married does not cause the declaration, but vice versa). But perhaps some alleged states with a double direction of fit are not causally self-referential: perhaps "besires", if they exist, are like beliefs and desires (which they are after all made of) in not being causally selfreferential. Be that as it may, it is clear that one must conceptually distinguish the idea that a representation has this or that direction of fit, and the idea that it is or is not causally self-referential in this or that way.

Further, representations that are not causally self-referential may nonetheless have causal or constitutive roles to play in creating states of affairs; and having such roles is also different from having a direction of fit. The desire that squirrel pelt is money might have causal and constitutive relevance for squirrel pelt being money, but nonetheless have just one direction of fit, as a desire. And the belief that squirrel pelt is money might have causal and constitutive relevance for squirrel pelt being money, but have just one direction of fit, as a belief. Perhaps both a desire and a belief can be present at the same time, and be causally relevant, and yet have just one direction of fit each. Further, many things and events may cause other events, or be constitutively related to their existence, without having a direction of fit at all. A stone can break a window without having a direction of fit, and the fact that Socrates died is constitutively related to the fact that Xanthippe became a widow, but the fact has no direction of fit. Imagining, or merely entertaining the thought, that squirrel pelt is money has no direction of fit, and nonetheless such states might play a role in the causal or constitutive story of squirrel pelt becoming money. My belief that it is raining has constitutive relevance for the state of affairs that "someone in this room believes it is raining", but nonetheless my belief has no direction of fit concerning the proposition that "someone in this room believes it is raining". And so on and so forth. Causing or constituting is one thing, having a direction of fit is another thing.

Thus, there is prima facie conceptual room for the possibility that even if declarations and other relevant representations do not have both directions of fit, they nonetheless can be both in the business of representing things and bringing things about. This paper does not challenge the causal 
self-referentiality of declarations or the remarkable powers of collective acceptance or declarations to create states of affairs by representing them as existing (which, as seen, have been compared by Searle to God's powers to create light by merely representing it as existing). It is just that these good ideas should not be cashed out in terms of a bad idea, the idea of attitudes with both directions of fit. The idea of anything having two directions of fit is problematic, so neither collective acceptance, nor declarations, nor God's thoughts about light have both directions of fit concerning the same propositional content.

\section{The first step of the argument: focus on cases of discrepancy}

In what follows, the argument against attitudes with double direction of fit is presented in three steps. The argument starts with the observation that the propositional content of for example a desire that $\mathrm{p}$ and a belief that $\mathrm{p}$ is identical; they both concern the state of affairs that $\mathrm{p}$. By contrast, the distinction of two directions of fit is to be used in describing how desires and beliefs differ. Similarly for the distinction between speech acts (assertives vs directives), and representations of other kinds (e.g. speed limit signs vs speed indicators). As we saw, Anscombe illustrated this distinction with an example of a shopper with a shopping list, being followed by a private detective writing down what the man puts into his shopping basket. The relevant states of affairs or propositions can be of any kind, say, "it is raining", "there are bananas in the shopping basket", "squirrel pelt is money", "I sit on the sofa", or "the driver drives 80 kilometers per hour".

It is worth pausing to stress that because their propositional content can be the same, the relevant difference (the direction of fit) between a desire and a belief is not manifest in the successful cases. A desire that $p$ is successful (that is, "fit" in the relevant sense) when it is the case that $p$, and likewise a belief that $\mathrm{p}$ is successful (that is, "fit" in the relevant sense) when it is the case that p. ${ }^{17}$

\footnotetext{
${ }^{17}$ There are of course other notions of fittingness or appropriateness, which are not at stake when directions of fit are discussed. One such is the normative relation between an attitude and the facts that call for such an attitude, making the attitude fitting or appropriate in a normative sense: for example fear is a fitting response to danger. Sometimes the notion of "direction of fit" is misleadingly used for this other normative notion of appropriateness - what is in this paper called a normative reading of a direction of fit is a different idea altogether. For example Gibbard (2008, 173) holds that the plan to go left, and the normative judgement that one should go left, in some sense "fit" the state of the world in which there is tiger to one's right. That is, the representation that $q$ fits the world when it is the case that $p$, if $\mathrm{p}$ makes $\mathrm{q}$ an appropriate response. This is fine, but then Gibbard misleadingly says that thereby the plan and the normative judgement have the "mind-to-world" direction of fit. But the "fit" in the notion of direction of fit (as used in this paper, and in the main usage in the debates) is not that kind of normative appropriateness, but identity of content. The judgement that one should go left has the "mind-to-world" direction of fit, if it has it at all, in relation to the fact that one should go left (assuming that there is such a fact). This notion of direction of fit between the representation and the world can then be understood dispositionally, normatively, or in some possible third way, in the way described here in
} 
Both a desire and a belief that it is raining are successful when it is raining. Similarly, the shopper's list is successful when the basket contains the same items as it; and the detective's list is successful when it contains the same items as the basket. Both lists are successful, when they list the same items as the basket. ${ }^{18}$

Thus, in drawing the distinction between desires and beliefs (or practical and theoretical representations in general) a reference is to be made to the unsuccessful cases, that is, cases of “discrepancy” as Anscombe $(1957, \S 32)$ calls them. (If there are infallible states, their direction of fit is to be defined with reference to counterfactual cases of discrepancy, see §8). In the unsuccessful cases we can ask which side ought to change (normative reading, §4-5), or tends to change (dispositional reading, §6) when there is a discrepancy.

Terminologically, the representation "fits" the world, and the world "fits" the representation when their content is identical. This can also be called the "happy" or "successful" case to avoid repetition. The opposite for the happy or successful case is the unhappy or unsuccessful case of "discrepancy".

As one cannot achieve the fit in the relevance sense if one drops any representations concerning $\mathrm{p}$ altogether (although one can of course avoid discrepancy that way), I focus on situations where some representation concerning $\mathrm{p}$ is adopted - the notion of "direction of fit" concerns such situations. There are exactly four possibilities, two happy and two discrepant situations:

1) it is the case that $p$, and the representation holds that $p$ is the case (the "yes-yes"-situation);

2 ) it is the case that not-p and the representation holds that not-p is the case (the "no-no"-situation)

3 ) it is the case that p but the representation holds that not-p is the case (the "yes-no" situation);

4) it is the case that not-p but the representation holds that $\mathrm{p}$ is the case (the "no-yes" situation). ${ }^{19}$

Of course, beliefs can be more or less precise, and closer and further from the full truth, or perhaps more or less "truthlike". There can be significant progress in beliefs even when full truth is not

sections $§ 3-\S 7$. It is important not to confuse the normative understanding of a direction of fit with the normative relation that Gibbard has in mind.

${ }^{18}$ Causally self-referential states, as discussed in $\S 2$, have further conditions of satisfaction.

${ }^{19}$ To illustrate, with the example of "there are bananas in the basket": 1) there are bananas in the basket, and the content of the belief, desire or other representation is that there are bananas in the basket; ("yes-yes"); 2) there are no bananas in the basket, and the content of the belief, desire or other representation is that there are no bananas in the basket ("nono"); 3) there are bananas in the basket, but the content of the belief, desire or other representation is that there are no bananas in the basket ("yes-no"); 4) there are no bananas in the basket, but the content of the belief, desire, or other representation is that there are bananas in the basket ("no-yes"). 
attained. Similarly, plans can be more or less successful and there can be significant progress even when full realization is not achieved. For simplicity, I will here ignore such questions of degree, and assume that the representations are of either-or kind: either squirrel pelt is money or it is not.

I will below use the technical term "reverse discrepancy" so that the reverse discrepancy of the situation 4 ("yes-no") holds in the situation 3 ("no-yes") and the reverse discrepancy of situation 3 ("no-yes") holds in the situation 4 ("yes-no"). They are each other's opposites both in what the case is and what the representation is. (To illustrate, the reverse discrepancy of there being bananas in the basket, but not on the list is the situation where there are not bananas in the basket, although there are bananas on the list). This will be crucial in the argument that follows. To anticipate, what is wrong with the putative representations with the double direction of fit is that that they contain the normative recommendation (in the normative reading) or dispositional tendency (in the dispositional reading) to oscillate between these two discrepant cases, never reaching the happy situation.

To recap, the first step of the argument is simply that in the situations 1 ("yes-yes") and 2 ("no-no"), there is no relevant distinction between theoretical and practical representations: the representation simply "fits" the world, and the "direction" of fit does not yet get purchase. That notion becomes relevant in situations of the type 3 ("yes-no") and 4 ("no-yes"), that is, in the unsuccessful or discrepant cases.

\section{The second step: the right and the wrong way to remove discrepancy}

According to the normative reading, the difference between the directions of fit amounts to the difference in what ought to happen in a case of discrepancy (cases of the type 3 or 4 ). The representation's direction of fit is "representation-to-world" if the representation (e.g. belief) is mistaken, or at fault, and ought to change. (For example, the detective's report ought to track the contents of the basket). And the representation's direction of fit is "world-to-representation" if the representation (e.g. desire) is not mistaken, not at fault, and it is rather the world which "should" change. (For example, the shopper should add bananas to the basket if the shopping list says so, and not delete bananas from the list merely because the basket does not yet contain bananas).

We can put this schematically, with reference to the four scenarios above. Concerning practical representations, in discrepant cases of type 3 ("yes-no"), the right move is to 2 ("no-no"), and the 
wrong move is to 1 ("yes-yes"), even though the move to 1 would solve the discrepancy as well. It is just that it is a wrong kind of move for an intention or command etc. (If the shopping list says "no bananas", it is a wrong move to tinker with the list merely because there are bananas in the basket to make it look like the shopping list contained bananas all along; the right move is to remove the bananas from the basket). And concerning practical representations, in discrepant cases of type 4 ("no-yes"), the right move is to 1 ("yes-yes") and the wrong move is to 2 ("no-no") even though that would solve the discrepancy as well. Again, it would be a wrong kind of move for an intention or command etc. (If the shopping list says "bananas", it is a wrong move to tinker with the list merely because there are no bananas in the basket - to make it look like the shopping list did not contain bananas after all; the right move is to add bananas to the basket).

Concerning theoretical representations, in discrepant cases of type (3), the right move is to (1) and the wrong move is to (2), even though that would solve the discrepancy as well. And concerning theoretical representations, in discrepant cases of type (4), the right move is to (2) and the wrong move is to (1), even though that would again solve the discrepancy. The wrong moves are wrong because what is at stake is a theoretical representation such as a belief, an assertion etc.

Thus we see that theoretical and practical representations differ in which end out to change in cases of discrepancy. That is what the widely supported normative reading of "directions of fit" amounts to. $^{20}$

In the quote above, Anscombe draws a normative distinction in terms of mistakes, as does Mark Platts in this oft-quoted passage:
"The distinction is in terms of the direction of fit of mental states to the world. Beliefs aim at being true, and their being true is their fitting the world; falsity is a decisive failing in a belief, and false beliefs should be discarded; beliefs should be changed to fit with the world, not vice versa. Desires aim at realization, and their realization is the world fitting with them; the fact that the indicative content of a desire is not realised in the world is not yet a failing in the desire, and not yet any reason to discard the desire; the world, crudely, should be changed to fit with our desires, not vice versa." (Platts, 1979, p. 257, italics added)

\footnotetext{
${ }^{20}$ One may of course be skeptical about any normative "shoulds" concerning mistaken beliefs or assertions and unfulfilled desires, intentions, promises or orders. But then one is skeptical about these representations having a direction of fit in the normative sense. This paper points out merely that nothing has both directions of fit, and the skeptics presumably do not challenge that.
} 
The normative reading is also endorsed by Searle:

"Perhaps a better term than "direction" would be "responsibility" for fitting. The belief is supposed to be true, and thus its responsibility is to match the world. It has the mind-toworld direction of fit. If the belief succeeds in achieving that fit, it is true, otherwise it is false. But if the desire or the intention fails, it is not the desire or intention that is at fault but the world which is, so to speak, at fault. And for this reason we can say that desires and intentions have the world-to-mind direction of fit or responsibility for fitting." (Searle 2010, 28 , italics added)

On the normative reading, to say that a representation that $\mathrm{p}$ has any direction of fit means that in the counterfactual or actual case that $\mathrm{p}$ is not the case, there is a right and a wrong way to make the representation satisfied. The constitutively wrong way is to tinker with the representation when the world is at fault, and to tinker with the world when the representation is at fault. Even though a belief comes to be true if one change's the world accordingly, it would be the wrong kind of response. For example, it would be a wrong kind of response from Anscombe's detective to add bananas to the man's shopping basket merely because the detective's report lists the item "bananas". And vice versa for desires, commands and practical representations: one should not drop them merely because the desired or commanded goal does not yet obtain. Representations with a different direction of fit thus differ on which end has to give, the representation or the world, so that the required kind of "fit"(success, identity of content) may be (re)gained?

\section{The punchline: why having both makes no sense}

To say that any representation has both directions of fit amounts to saying that in the case of discrepancy the fault lies both with the representation which should change - and the fault lies with the world, which also should change. Both should change simultaneously. But changing both the world and the representation would not bring about the required "fit" (success, identity of content), but a reverse lack of "fit" (a reverse failure, reverse discrepancy). The idea of two directions of fit is thus a recipe for making the fit impossible to regain. To the question "which end has to give?" the answer "both ends" is peculiarly catastrophic or absurd.

Take the situation 3, ("yes-no") where it is the case that p but the representation that not-p is adopted. As we saw, if the representation is "practical" the adviced move is to 2 ("no-no"), and if it 
is "theoretical" the adviced move is to 1 ("yes-yes"). Both are happy solutions and the fit is regained and in the right way. But if the representation has both directions of fit, both ends ought to change (the case from $p$ to not-p and the representation from not-p to $p$ ) so the adviced move from 3 ("yes-no") is to the other discrepant scenario 4 ("no-yes"). The fit is not gained.

Take, then, the other discrepant scenario 4 ("no-yes") where it is the case that not-p and the representation that $\mathrm{p}$ is adopted. Again, if the representation is practical, the adviced move is to 1 ("yes-yes"), and if theoretical, to 2 ("no-no"). Both are happy solutions and the fit is regained, in the constitutively right way. But if the representation has both directions of fit, both ends ought to change (the case from not-p to $p$, and the representation from $p$ to not-p) so the adviced move from (4, "no-yes") is to the other discrepant scenario 3 ("yes-no"). The fit is not gained.

Thus, the advice amounts to infinite oscillation from (4) to (3), and from (3) to (4). This is the normative advice that the idea of both directions of fit burdens the representation with, in a constitutive manner. The representation would certainly be better off without such a burden.

Thus, even if human declarations and collective acceptances would be much like Creator God's representations, it would not be advisable to think of them as having both directions of fit.

To recap, here are the three steps of the argument:

1) In order to distinguish states with different directions of fit one has to focus on the (counterfactual or actual) cases where there's a discrepancy between the representation and the world: in the happy cases with no discrepancy, the perfect fit is between the representation that $p$ and it being the case that $\mathrm{p}$, both in theoretical and practical cases.

2) The idea of two directions of fit means that for any discrepancy, there's (constitutively) a right and a wrong way of (re)gaining fit: in the case of theoretical representations one should change one's representation, in the practical case the world should change (but not the other way around). 3) A state with both directions of fit constitutively carries the suggestion that in the case of discrepancy, both one's representation should change and the world should change. This would merely bring about the reverse discrepancy (so both ends should change again, not removing the discrepancy; and so on).

\section{The argument on the dispositional reading}


A somewhat similar argument can be given for the dispositional reading (M. Smith 1987). The dispositional reading of the notion of a direction of fit is made in terms of tendencies, not "shoulds".

"For the difference between beliefs and desires in terms of direction of fit comes down to a difference between the counterfactual dependence of a belief and a desire that $p$, on a perception that not p: roughly, a belief that $\mathrm{p}$ is a state that tends to go out of existence in the presence of a perception that not $\mathrm{p}$, whereas a desire that $\mathrm{p}$ is a state that tends to endure, disposing a subject in that state to bring it about that $\mathrm{p}$. Thus, we may say, attributions of beliefs and desires require that different kinds of counterfactuals are true of the subjects to whom they are attributed. We may say that this is what a difference in their direction of fit is." (M. Smith, 1987, p. 54; italics added) $)^{21}$

The argument presented above can be restated for the dispositional understanding (the first step remains the same):

1) To distinguish states with different directions of fit one has to focus on the (counterfactual or actual) cases where there's a discrepancy between the representation and the world: in the cases with no discrepancy, the perfect fit is between the representation that $p$ and it being the case that $p$, both in theoretical and practical cases.

2') the idea of two directions of fit means that there are two opposite tendencies: in situations of discrepancy, in the case of theoretical representations the representation tends to change, in the practical case the representation tends to endure, disposing a subject in that state to bring it about that $\mathrm{p}$.

3') a representation with both directions of fit has two tendencies which cancel each other out, being of no use in trying to (re)gain the fit between the representation and the world.

Thus, whether one opts for a normative or a dispositional reading of the distinction, the idea of representations with a double direction of fit is in trouble. As mentioned above, this is no longer news in the debates on moral motivation, but it is nonetheless bad news for the debates on collective acceptance. Worse news in fact, as one move which is available and satisfactory concerning moral motivation (the two directions of fit that a representation has concern different propositional

\footnotetext{
${ }^{21}$ Smith here refers to "perceptions that p", whereas Searle regards perceptions that $\mathrm{p}$ already as having the direction of fit of beliefs, and additionally a self-referential causal role. It is perhaps better to have the criterion in a looser form "finding out that p" but even that may be too closely tied to the belief that $p$ : finding out that $p$, or perceiving that $p$, is indeed very close to believing that $\mathrm{p}$.
} 
contents) is not so concerning collective acceptance (where the representation is meant to bring about precisely the represented state of affairs).

\section{A third way?}

In addition to the normative and dispositional analyses of the concept of a "direction of fit", other ones have not really been presented. But it is worth asking whether there could be a way out, by rejecting both the normative and the dispositional readings ${ }^{22}$ Especially one strategy suggests itself, but I doubt its prospects. This strategy would consist in rejecting the first step that both of the arguments above share, by holding that theoretical representations (e.g. beliefs) and practical representations (e.g. intentions) differ in the happy, successful cases as well in ways which need not refer to the actual or counterfactual cases of discrepancy.

There is some textual evidence that Searle may have had something like this in mind (although more clearly he seems to support the normative reading) at least concerning mental states:

"A good clue is this: if you can literally say of the mental state that it can be true or false, then it is likely to have the mind-to-world direction of fit because truth and falsity are the standard terms for assessing success or failure in achieving the mind-toworld $\downarrow$ direction of fit. Beliefs can be true or false but desires and intentions cannot. (Tiresomely, in English we do sometimes say, "My wish came true.” All the same, wishes are not literally true or false.) Desires and intentions can be satisfied or frustrated, carried out or not carried out; these are marks of the fact that they do not have the mind-to-world but the world-to-mind direction of fit." (Searle 2010, 28)

The idea is that the distinction between two directions of fit is really about two ways of succeeding (and not about what should happen or tends to happen in cases of failure). ${ }^{23}$ Put formally, successful beliefs have the feature X but not the feature Y (e.g. 'true' but not 'carried out'), successful desires and intentions have the feature $\mathrm{Y}$ but not the feature $\mathrm{X}$ (e.g. 'carried out' but not 'true'), where some other kinds of representations (declarations? collective acceptance? besires?) can be both $\mathrm{X}$ and $\mathrm{Y}$ when successful. Thus these can have both directions of fit, in the successful cases at least. ${ }^{24}$

\footnotetext{
${ }^{22}$ I thank Raul Hakli for pressing this point.

${ }^{23}$ Cf. Dancy 1993, chapter 2.

${ }^{24}$ The features X and Y must be logically independent in such a way that it is possible for beliefs to have X but not $\mathrm{Y}$, and for desires and intentions to have $\mathrm{Y}$ but not $\mathrm{X}$. They may however be connected in the sense that declarations have
} 
There are two challenges that this suggestion will have to face. The first is identifying the characteristics $\mathrm{X}$ and $\mathrm{Y}$. None of the readily available candidates will do. Concerning beliefs, the natural suggestion is that they can be true whereas desires and intentions cannot. But in the case of a successful desire, the propositional content is true as well. Searle however stresses that the attitude itself, the belief - and not merely its content - can be true. It remains unclear whether that move will be of help, but the main trouble concerns the feature $Y$ that desires, intentions and suchlike are meant to share -they are meant to have the same direction of fit. Desires are satisfied and intentions are carried out, writes Searle. "Satisfaction" cannot be a criterion for only some states, because all intentional states have conditions of satisfaction according to Searle. ${ }^{25}$ It is too general, as also beliefs have conditions of satisfaction. "Carrying out" is too specific, as desires as opposed to intentions need not be carried out in order to be satisfied or successful. "Being fulfilled" is again too general, as some states with the direction of fit of beliefs, such as prophesies, can be fulfilled. Thus, it remains unclear whether a characterization of $\mathrm{Y}$ ( or X) can be found which will work. Such states as beliefs, desires and intentions etc. may differ in all sorts of ways, but these many differences seem to be irrelevant for the idea of two directions of fit which is meant to distinguish theoretical and practical representations from one another. To do this, positive characterizations for $\mathrm{X}$ (what all theoretical representations have in common so that they differ from practical ones) and $\mathrm{Y}$ (what all practical representations have in common so that they differ from the theoretical ones) should be found.

Supposing such positive characteristics can be found, would it be of any help for this reading? Not unless it can tackle the second challenge. The second challenge is that this strategy would have to say something about the cases of discrepancy as well. (Supposedly any state, act, attitude or representation has the direction of fit it has both in the successful and unsuccessful cases.) If this approach analyses the negative cases along the normative or dispositional lines, no progress has been made - the oscillation between the reverse discrepancies is again the unwanted result. Another option is to cover the negative cases as well, and state something, which is neither dispositional nor normative. Perhaps it can be merely descriptive: "there are two ways in which declarations or

feature X only because they have feature Y, and have the feature X only if they have feature X. I thank Beatrice Kobow for pointing out this possibility.

25 "I introduce a name for the conditions in the world which must be satisfied if the intentional state is to be satisfied: conditions of satisfaction. We can think of all of the intentional states that have a whole propositional content and a direction of fit as representations of their conditions of satisfaction. A belief represents its truth conditions, a desire represents its fulfillment conditions, an intention represents its carrying out conditions. The key to understanding intentionality, at least for these simple cases, is "representation" in a very specific sense. The intentional state represents its conditions of satisfaction." (Searle 2010, 29). 
collective acceptances could in principle fail, they can be untrue (or X) like beliefs and unfulfilled (or Y) like desires, but this as such tells us nothing about which end should change, or has a disposition to change". Concerning many features (such as being blue and being soft) a thing can have or lack both features and this as such has no dispositional or normative consequences. But this strategy would have to defend the suggestion that states like beliefs or intentions and so on would have no constitutive normative or dispositional connection to how things are (or are perceived to be). It is hard to estimate in advance whether or not a suggestion like this would work; this issue can be delayed until the first challenge is met and candidates for the $\mathrm{X}$ and $\mathrm{Y}$ terms are found.

\section{Infallibility of "factive" representations}

One issue which can be taken up at this stage concerns infallibility. Perhaps the central candidates for having both directions of fit in the field of institutional ontology, such as declarations and collective acceptance, are such that they cannot fail. If they are infallible, is the argumentation above which appeals to the discrepant cases relevant at all ${ }^{26}$

There are of course such factive concepts, for example knowledge, memory or perception. One can know, remember or perceive that $\mathrm{p}$ only if it is in fact the case that $\mathrm{p}$. Otherwise one merely believes, or seems to remember, and it merely visually seems to one that $\mathrm{p}$. Something simply is not knowledge, but merely "knowledge" or subjective epistemic certainty, if it is not true. Perhaps similar analysis of declarations or collective acceptance is correct: unless it is the case that $\mathrm{p}$, the relevant agents have not in fact declared or collectively accepted that $\mathrm{p} .{ }^{27}$

The idea that declarations by definition cannot fail has intuitive appeal. If some putative case of declaration or collective acceptance fails, it is indeed only a putative case of declaration or collective acceptance instead of the real thing. Of course, what are otherwise like declarations or collective acceptances can fail. One way in which they can fail is that normative conditions that seemingly are at place are not so in fact: say, one cannot marry someone else because one's spouse

\footnotetext{
${ }^{26}$ We have above seen that direction of fit is a separate idea from causal self-referentiality. Perhaps declarations are causally self-referential: a priest's declaration is satisfied only if the couple becomes a married couple thanks to that very declaration. If the couple is already married, the declaration is not a satisfied one. The idea of infallibility adds that perhaps it is a declaration only if it is a satisfied one. "Knowledge" is not causally self-referential but is factive, "perception" and "memory" are both causally self-referential and factive.

${ }^{27}$ Compare to "belief": it would not be a plausible idea to suggest that an apparent belief is not really a belief if it is not true. It is of course true that one can always simply stipulate that such and such is infallible by definition, but concerning some concepts (such as belief) it does not seem like a good idea, while concerning other concepts (such as knowledge) it does.
} 
hasn't died and one hasn't divorced, or the couple to be wed is already married to one another. Or then, the normative standing of the declarer (say, priest) has expired and he or she no longer has the power to do the declaration (say, his or her date of retirement was the day before, but for some miscalculation he or she had forgotten about it). But one can stick to the view that these are merely apparent or putative declarations.

It may be of interest that John Searle has in personal communication (as a response to the argument presented in this paper) told, perhaps surprisingly, that he does not think declarations are infallible. He thinks that declarations can fail, but the fault lies sometimes with the representation and sometimes with the world. It is of course interesting to know that that would be the kind of solution that he would try to defend, but it is hard to square this with the view that declarations have both directions of fit: that would amount to giving up the idea that one and the same representation has both directions of fit. It seems that to cash out this intuition Searle would have to maintain that a declaration expresses in fact two representations with the same content but a different direction of fit - and these two representations can fail independently of one another.

But no doubt many others think that declarations or collective acceptances are by definition infallible, and that such an appeal to infallibility will pre-empt the whole argument presented above. Here I need not argue against (or for) the view that there are such representations, perhaps declarations, that are infallible by definition. It is just that that the infallibility does not help to justify the view that the representations have two directions of fit. If an infallible representation has a direction of fit, there are requirements concerning what should happen (in the normative reading) or tends to happen (in the dispositional reading) in cases of discrepancy - that is what it is to have a direction of fit (unless some third definition turns out to be correct despite the reservations made above).

It may seem pointless to burden an infallible representation with such requirements or dispositions. If so, then dropping the idea that it has directions of fit is a remedy. Indeed, it is hard to see a motivation for someone to defend the view that some representation is infallible, and nonetheless it has a direction of fit, once the direction of fit is defined in the normative or dispositional way. (By contrast, there is good motivation to hold the view that declarations or collective acceptances are infallible, and causally or constitutively responsible for the existence of what they represent - it is just that that view does not commit one to anything having two directions of fit). 
But perhaps infallible representations nonetheless differ as to their direction of fit. We can imagine an infallible being (God) which is infallible in its beliefs, and nonetheless we can make sense contrafactually of such beliefs having the direction of fit of beliefs. If the God would per impossibile have a mistaken belief, the direction of fit is such that it should change the belief and not the world. We can accordingly imagine a being (another God) with such desires that they are unmistakenly fulfilled. Nonetheless, these desires have the opposite direction of fit to beliefs. Infallibility as such does not prevent us from asking what should happen in the case of discrepancy. The answer can perhaps be part of the definition of the representation in question - part of what makes it a belief or a desire. Thus, pointing out that such cases never arise does not take away the burden of answering what constitutively should happen, or tends to happen, or would be the case, in such contrafactual cases. ${ }^{28}$ And the answer, in the cases where the representation allegedly has two directions of fit, is catastrophically bad, or so this paper has argued.

\section{Conclusion}

Above I have analysed the notion of direction of fit as a feature of propositional attitudes, speech acts and indeed any representations, and argued that given what "direction of fit" means, nothing can have both directions of fit. Apart from that, this paper has not given substantive reasons for or against any view in the ontology of institutions, Searlean or non-Searlean. Dropping all talk of representations with two directions of fit is a rather minimal revision in any position that has so far included the idea of double direction of fit.

One way to proceed is to suggest that there are two separate attitudes or representations at stake, which each have a direction of fit quite unproblematically. Perhaps one and the same speech act can express two such separate attitudes. ${ }^{29}$ This would seem to me to be the way to go for Searle given his point above about how in the case of failed declarations, sometimes it is the representation, and sometimes the world that is at fault.

Another option might be to think that whereas each attitude individually has one direction of fit, the collection of such attitudes has the other direction of fit. Searle $(2010,104)$ has expressed

\footnotetext{
${ }^{28}$ It may of course make difference whether it is the possessor of the state, God, that is infallible, or whether it is the kind of state in question, say collective acceptance, that is infallible.

${ }^{29}$ This suggestion seems to be included e.g. in A. Meijers's $(2007,106)$ discussion of collective speect acts.
} 
something like that idea as well, in speaking about the "cumulative direction of fit" of the daily use of a vocabulary. ${ }^{30}$

Finally, it should be kept in mind that from the fact that some attitude or act or representation brings something about (for example the collective acceptance that squirrel pelt is money brings it about that squirrel pelt is money) it does not follow that the attitude has this or that direction of fit. Given the difficulties with the idea of representations with double direction of fit, it would be best to focus on analyzing how our acts and attitudes create, constitute and maintain the institutional reality, and not let the idea of direction of fit disturb the analysis. ${ }^{31}$ Being causally or constitutively relevant for something else's existence is a separate idea from that of having a direction of fit, and so rejecting the idea that declarations or anything else have both directions of fit does not amount to rejecting the causal or constitutive relevance of these attitudes or acts. Of course, there may be other reasons to reject their causal or constitutive relevance. This paper has neither defended or criticized that idea, but has tried to show that there are conclusive reasons to reject the idea of anything having both directions of fit.

\section{Literature}

G.E.M. Anscombe (1957), Intention. Oxford: Basil Blackwell.

J. L. Austin (1953), "How to Talk: Some Simple Ways," Proceedings of the Aristotelian Society, Vol.53, 227-246.

Jonathan Dancy (1993), Moral Reasons. Oxford, Blackwell.

Allan Gibbard (2008), Reconciling our Aims. In Search of Bases for Ethics. Oxford, Oxford University Press.

Raul Hakli (2012), ’Direction of Fit and Direction of Fix”, unpublished manuscript. Frank Hindriks (2011), "Restructuring Searle's Making the Social World”, Philosophy of the Social Sciences,

I. L. Humberstone (1992), "Direction of Fit," Mind, 101, 59-84.

\footnotetext{
30 "So the daily use of the vocabulary with the downhill direction of fit already has a cumulative uphill direction of fit in sustaining the existence of the status functions across time." (Searle 2010, 104).

${ }^{31}$ I would like to thank Christopher Gauker, Raul Hakli, Antti Heikinheimo, Matti Heinonen, Frank Hindriks, Onni Hirvonen, Kent Hurtig, Heikki Ikäheimo, Beatrice Kobow, Eerik Lagerspetz, Kaarlo Miller, Pekka Mäkelä, Nikos Psarros, Alessandro Salice, Mikko Salmela, Hans Bernhard Schmid, Michael Schmitz, David Schweikard, John Searle, Teemu Toppinen, Luca Tummolini, Maj Tuomela, Raimo Tuomela, Trevor Wedman, and other participants in workshops "Normativity and metaphysics", November 2010, Helsinki; The social ontology and collective intentionality reading group, Helsinki December 2010; "Colloquium in Social Ontology", April 2011, Helsinki; "European Network of Social Ontology", September 2011, Rome; "Talous”, January 2012, Helsinki; "Social Ontology \& Philosophy of the Social Sciences", June 2012, Vienna; "Natural and Social Ontology", Leipzig July 2012, and a visiting lecture on Searle's social ontology, Macquarie March 2013.
} 
Eerik Lagerspetz (2006), “Institutional Facts, Performativity and False Beliefs,” Cognitive Systems Research, 7: 2-3, 298-306.

Anthony Meijers (2007), “Collective Speech Acts”, in Savas L. Tsohatzidis (ed.) Intentional Acts and Institutional Facts, Springer.

Richard Moran \& Martin J. Stone (2009) “Anscombe on expression of intention” in Constantine Sandis (ed.), New Essays on the Explanation of Action. Palgrave Macmillan.

Mark Platts (1979), Ways of Meaning. London: Routledge and Kegan Paul.

Huw Price (1989), "Defending Desire-as-Belief,” Mind, 98, 119-127.

John Searle (1969), Speech Acts: An Essay in the Philosophy of Language, Cambridge: Cambridge University Press.

John Searle (1983), Intentionality. An Essay in the Philosophy of Mind. Cambridge: Cambridge University Press.

John Searle (1995), The Construction of Social Reality. Cambridge: Cambridge University Press. John Searle (1999) Mind, Language and Society: Doing Philosophy in the Real World, Basic Books.

John Searle (2007), "What is Language: Some Preliminary Remarks”, in Savas L. Tsohatzidis (ed.), John Searle's Philosophy of Language: Force, Meaning and Mind, Cambridge University Press.

John Searle (2010), Making the Social World. The Structure of Human Civilization. Oxford: Oxford University Press.

John Searle (2011), "Replies", Analysis 71(4): 733-741.

Michael Smith (1987), “The Humean Theory of Motivation,” Mind, 96, 36-61.

David Sobel \& David Copp (2001), "Against Direction of Fit Accounts of Belief and Desire," Analysis 61 (1), 44-53.

Sergio Tenenbaum (2006), "Direction of Fit and Motivational Cognitivism," in Russ Shafer-Landau (ed.), Oxford Studies in Metaethics. Oxford: Oxford University Press.

Savas L. Tsohatzidis (2010) "Review of John R. Searle, Making the Social World: The Structure of Human Civilization," Notre Dame Philosophical Reviews

Raimo Tuomela (2007), Philosophy of Sociality, Oxford: Oxford University Press.

Raimo Tuomela (2011), “Searle's New Construction of Social Reality”, Analysis 71(4): 706-719.

Bernard Williams (1966), "The Inaugural Address: Consistency and Realism," Proceedings of the Aristotelian Society, Supplementary Volumes 40, 1-22.

J. David Velleman (1992), “The Guise of the Good,” Noûs, Vol.26, No.1, (March 1992), pp. 3-26. Nick Zangwill (1998), "Direction of Fit and Normative Functionalism,” Philosophical Studies, 91 (2), 173-203. 